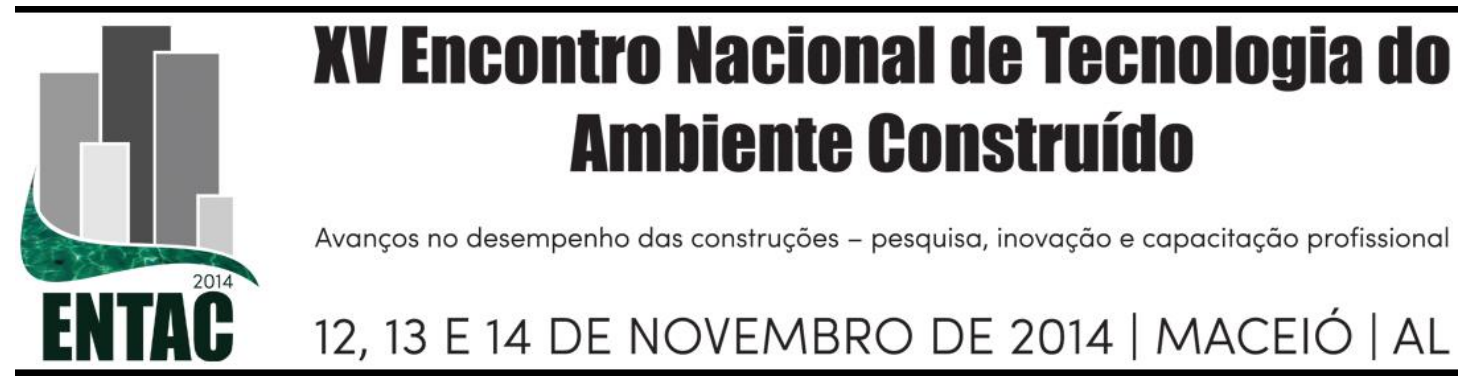

\title{
ASPECTOS ECONÔMICOS DA CONSTRUÇÃO CIVIL NO BRASIL
}

\author{
FIALHO, Karlo Eugênio Romero (1); COSTA, Heloína Nogueira da (2); LIMA, \\ Sérgio Henrique de Oliveira (3); BARROS NETO, José de Paula (4) \\ (1) Universidade Federal do Ceará, e-mail: karloerf71@ @otmail.com, (2) Universidade Federal do Ceará, \\ e-mail: heloinan@ hotmail.com, (3) Universidade Federal do Ceará, e-mail: shlima05@gmail.com, (4) \\ Universidade Federal do Ceará, e-mail: barrosneto@gercon.ufc.br
}

\begin{abstract}
RESUMO
A indústria da construção civil sofre influências de um conjunto de fatores que se relacionam dinamicamente com o setor. Políticas econômicas que proporcionaram o crescimento da renda familiar e do emprego, aumento do crédito ao consumidor, maior oferta de crédito imobiliário e manutenção da redução do Imposto sobre Produtos Industrializados (IPI) de diversos insumos da construção foram responsáveis pelo crescimento do setor nos últimos anos. A indústria da construção civil exerce influência sobre diversos setores da economia, seja através de sua alta taxa de geração de emprego, renda e impostos, ou pela geração de demanda em outros setores. O papel da construção civil como vetor do crescimento econômico é usualmente mensurado pelo tamanho relativo do seu produto como proporcionalmente à renda nacional e por sua ampla rede de ligações setoriais e elevado efeito multiplicador de emprego. Outra característica deste setor é a baixa demanda por importações, o que não pressiona a balança comercial com o aumento de sua atividade. Estudar a economia da construção é vital para se compreender sua dinâmica e os fatores políticos, sociais e econômicos que estão ligados ao seu desenvolvimento. Portanto, o objetivo deste trabalho é analisar os aspectos econômicos da construção civil no Brasil, baseando-se em informações e indicadores dos últimos anos. Trata-se de uma pesquisa qualitativa exploratória, utilizando análise documental. Os documentos analisados são relatórios de órgãos oficiais (como IBGE, BNDES, Ministérios) e instituições de classe (SINDUSCONs, CBIC, ABRAMAT). Os resultados obtidos confirmam a relevância do setor para a economia: em média, o setor cresceu a uma taxa anual de 5\%; a participação no PIB passou de 4,7\% para 5,7\% nos últimos 10 anos; houve também um aumento de 52\% no nível de emprego. A partir destes resultados, podem-se gerar perspectivas para o desenvolvimento do setor e da economia geral para os próximos anos.
\end{abstract}

Palavras-chaves: Economia; Construção Civil; Indicadores Econômicos.

\begin{abstract}
The Construction industry is influenced by a number of factors that dynamically relate to the sector. Economic policies that led to growth of family income and employment, increase in consumer credit, increase in supply of mortgage credit and the reduction of the Excise Tax of a number of construction inputs, were responsible for the growth of the sector in recent years. Construction influences a number of economic sectors, either through its high rate of employment, income, and taxes generation, or its capacity to generate demand in other industries. The influential role of Construction as a vector of economic growth is usually measured by the relative size of their aggregate output as a proportion of national one and by its wide network of industry connections and high employment multiplier effect. Another feature of this sector is the non-significant demand for imports, which does not affect the trade balance whilst the activity increases. Investigating the economics of Construction has paramount importance to understand its dynamics, the major political, social and economic factors that are directly
\end{abstract}


related to its development. Thus, the key purpose of this paper is to analyze the economic aspects of Construction in Brazil, based on economic indicators from recent years. This is an exploratory qualitative research, applying the documental analysis technique. Documents are economic reports issued by Brazilian government bodies (e.g. IBGE, BNDES, and Ministries) and sectorial institutions (e.g. SINDUSCONs, CBIC, and ABRAMAT). Results confirm the relevance of the sector for the economy: on average, the sector grew at an annual rate of 5\%; its share of Brazilian GDP increased from $4.7 \%$ to $5.7 \%$ over the last 10 years; there was also a 52\% increase in employment level. From these results, it is possible to generate prospects for development of the sector and the whole economy for coming years.

Keywords: Economics, Construction, Indicators.

\section{INTRODUÇÃO}

Extenso, complexo, dinâmico e relevante são termos comumente imputados, por autores de publicações científicas, em trabalhos que envolvam estudos sobre o setor da Construção Civil (CC) em relação aos aspectos econômicos que o envolvem. Por sua vez, Kureski et al. (2008) frisam que a CC exerce forte alavancagem nos setores que lhe servem de fornecedores de insumo. Assim, analisando a cadeia produtiva percebe-se a forte ligação com outros setores de atividades como a indústria de matéria-prima, serviços e equipamentos, conforme Gondin et al. (2004), gerando efeitos de estímulo positivo em outros setores.

A complexidade do setor advém dos vários impactos decorrentes sobre os aspectos econômicos, sociais, tecnológicos e governamentais que se inter-relacionam na dinâmica do segmento, envolvendo interesses do governo, das empresas e do cidadão. Sua importância, sob o ponto de vista econômico, é facilmente evidenciada pelo peso dos indicadores em relação à participação no PIB, na produção e no emprego, assim confrontados, em relação aos demais indicadores de outros setores da economia (KURESKI et al., 2008).

Como características deste setor, têm-se: os elevados investimentos exigidos para se manter no setor, baixa exigência de qualificação da mão-de-obra e baixa produtividade. Mesmo assim diante destas características, o setor é dinâmico e produz impacto para a economia do país, de tal forma que estudos apontam como setor-chave (KURESKI et al., 2008; TEIXEIRA; CARVALHO, 2005), condizendo com investimentos realizados pelo governo como ação para o desenvolvimento do país.

Embora o reconhecimento da relevância do setor para a economia, segundo Teixeira e Carvalho (2005) evidenciam que são poucos os estudos da área econômica sobre o segmento da CC. Assim, o objetivo deste artigo é investigar os aspectos econômicos da $\mathrm{CC}$, analisando os indicadores do setor dos últimos 10 anos. Ainda segundos os autores, a realidade é que poucos trabalhos focam o estudo das características do setor em relação aos seus efeitos sobre a economia, não se encontrando na literatura, estudos avaliando o significado e a relação para a economia, por meio da avaliação dos indicadores consagrados no campo econômico, como o PIB, FBCF, geração de emprego, investimento, financiamento, produção física industrial (TEIXEIRA; CARVALHO, 2005). Assim, investigar os aspectos econômicos da CC no Brasil implica uma análise cuidadosa dos principais indicadores, sua evolução e a interpretação de seus significados para o desenvolvimento de um importante setor para a economia brasileira em geral.

Além da presente introdução, este artigo está subdividido em outras cinco seções: na segunda seção, abordar-se-á brevemente acerca da metodologia empregada no estudo; em seguida, serão discutidos os principais aspectos econômicos da construção civil, a partir de indicadores de órgãos governamentais e instituições de classe; na quarta seção são discutidos os resultados do estudo, seguidos de uma seção de considerações finais; ao final do trabalho são apresentadas as referências que basearam a pesquisa. 


\title{
2 METODOLOGIA
}

Documentos são uma valiosa fonte de informações em pesquisa qualitativa, e consistem de arquivos públicos ou privados que os pesquisadores qualitativos podem obter (CRESWELL, 2012). Entre as suas vantagens, segundo Cellard (2010), pode-se destacar a mitigação de influências externas pela intervenção do pesquisador.

A metodologia para o desenvolvimento deste estudo baseou-se na consulta de dados de instituições como o Instituto Brasileiro de Geografia e Estatística (IBGE), Ministério do Trabalho e Emprego (MTE), Banco Nacional do Desenvolvimento Econômico e Social (BNDES), Câmara Brasileira da Indústria da Construção (CBIC), Sindicatos da Indústria da CC (SINDUSCONs). Os dados foram levantados e organizados para o período compreendido entre 2001 e 2013 - sempre que disponíveis - e referem-se aos principais indicadores relacionados ao setor, sendo estes confrontados às diversas análises e considerações presentes na literatura acadêmica e em reportagens e publicações referentes ao assunto pesquisado, tendo como resultado uma análise exploratória quanto aos aspectos econômicos da construção civil. Os principais indicadores analisados foram: Produto interno bruto (PIB); Valor adicionado bruto da $\mathrm{CC}$, geração de emprego e renda, financiamentos do Sistema Brasileiro de Poupança e Empréstimo (SBPE), Formação Bruta de Capital Fixo (FBCF), taxa de investimentos na construção civil.

\section{ASPECTOS ECONÔMICOS DA CONSTRUÇÃO CIVIL}

Teixeira e Carvalho (2005) reforçam a importância da construção civil para o desenvolvimento econômico, ao argumentarem em favor da priorização dos investimentos no setor, por seus efeitos diretos, indiretos e induzidos na produção, emprego, renda e arrecadação. Segundo as autoras,

\begin{abstract}
A forte interligação para trás da indústria da construção com outras atividades permite classificá-la como um setor-chave da economia brasileira. (...) é uma atividade que complementa a base produtiva e cria externalidades positivas que aumentam a produtividade dos fatores de produção e incentivam as inversões privadas, sendo de importância estratégica para a sustentação do desenvolvimento econômico e social brasileiro (TEIXEIRA; CARVALHO, 2005, p. 9).
\end{abstract}

Nas economias em desenvolvimento, o setor da $\mathrm{CC}$ é tipicamente mais vigoroso que outros setores nas primeiras fases de desenvolvimento econômico, em virtude do processo de industrialização e urbanização experimentado por alguns países. Dessa forma, em países menos desenvolvidos, o desenvolvimento econômico leva ao aumento da participação da indústria da CC no PIB (BON, 1992).

É comum analisar a relevância de um determinado setor para uma economia através da investigação de sua contribuição para a geração da riqueza total gerada por esta região (país, estado ou cidade). O Produto Interno Bruto (PIB) tem sido uma medida de análise consagrada para este fim, pelo que se justifica sua adoção neste trabalho.

Convém destacar que o PIB pode ser calculado a partir de três perspectivas (SOUZA, 2012): ótica da produção, ótica da demanda e ótica da renda. Por se tratar da análise de um setor (CC), as perspectivas mais adequadas são aquelas da produção e da demanda, que representam, respectivamente, quanto um setor econômico está produzindo ao mercado (a jusante), e quanto ele está demandando em insumos do mercado fornecedor (a montante). Destarte, os indicadores que serão abordados neste estudo são: (i) formação bruta de capital fixo; (ii) valor adicionado bruto; (iii) taxa de investimento e nível de investimentos; (iv) nível de geração de empregos. Esses indicadores refletem a dinâmica do setor e permitem comparações com índices da economia como um todo.

\subsection{Indicadores do setor e seus aspectos econômicos}


Segundo Zerkowski (1979), indicadores econômicos são informações que visam a fornecer uma noção de tendência da ação econômica. Portanto, avaliar os indicadores da CC permitirá compreender a relevância do setor e seu impacto na economia brasileira.

\subsubsection{Formação bruta de capital fixo (FBCF)}

A partir da ótica da demanda, a Formação Bruta de Capital Fixo (FBCF) representa a soma de todas as despesas com novos investimentos aplicados em bens de capital voltados à produção ou geração de riqueza (O'SULLIVAN; SHEFFRIN; NISHIJIMA, 2004). Exemplos destes investimentos são máquinas e equipamentos industriais, caminhões e tratores. De acordo com o IBGE (2008), a FBCF é a soma de todos os "acréscimos ao estoque de bens duráveis destinados ao uso das unidades produtivas, realizados em cada ano, visando ao aumento da capacidade produtiva do País". Trata-se, assim, de um importante indicador de vigor econômico, pelo que será aqui abordado.

De acordo com o IBGE (2013), o setor da CC é responsável por aproximadamente $42 \%$ da FBCF total brasileira, embora esta contribuição tenha atingido patamares superiores a $45 \%$ nos primeiros anos da última década, como mostra a Tabela 1. Este dado revela elevada concentração do investimento em capital produtivo brasileiro na indústria da $\mathrm{CC}$, conferindo ao setor, neste aspecto, importância relativa superior aos demais setores.

Tabela 1 - Evolução da participação relativa da FBCF da Construção Civil

\begin{tabular}{c|c|c|c|c|c|c|c|c|c|c|c|c|c}
\hline Ano & 2001 & 2002 & 2003 & 2004 & 2005 & 2006 & 2007 & 2008 & 2009 & 2010 & 2011 & 2012 & 2013 \\
\hline $\begin{array}{c}\text { FBCF CONST. } \\
\text { CIVIL / FBCF } \\
\text { TOTAL }\end{array}$ & $46,5 \%$ & $47,3 \%$ & $44,2 \%$ & $43,7 \%$ & $42,3 \%$ & $40,4 \%$ & $38,3 \%$ & $36,3 \%$ & $42,3 \%$ & $40,6 \%$ & $41,4 \%$ & $43,8 \%$ & $41,8 \%$ \\
\hline
\end{tabular}

Fonte: CBIC (2014).

O ano de 2008 apresentou a menor contribuição relativa da CC na FBCF brasileira $(36,3 \%)$. Entretanto, convém notar que não se tratou de um ano com queda nos investimentos produtivos em termos absolutos. De fato, a relação com a FBCF total brasileira caiu, embora os investimentos tenham aumentado em mais de $18 \% \mathrm{em}$ comparação com 2007, conforme observado na Tabela 2.

Tabela 2 - Evolução da formação bruta de capital fixo da Construção Civil

\begin{tabular}{c|c|c|c|c|c|r|r|r|r|r|r|r|c}
\hline Ano & 2001 & 2002 & 2003 & 2004 & 2005 & 2006 & 2007 & 2008 & 2009 & 2010 & 2011 & 2012 & 2013 \\
\hline $\begin{array}{c}\text { FBCF } \\
\text { (R\$ Bilhões) }\end{array}$ & 103,07 & 114,52 & 114,77 & 136,67 & 144,71 & 157,39 & 177,82 & 210,43 & 247,55 & 298,23 & 330,37 & 349,27 & 371,68 \\
\hline $\begin{array}{c}\text { Var. Anual } \\
\text { (\%) }\end{array}$ & - & 11,11 & 0,22 & 19,08 & 5,88 & 8,76 & 12,98 & 18,34 & 17,64 & 20,47 & 10,78 & 5,72 & 6,42 \\
\hline
\end{tabular}

Fonte: CBIC (2014).

De acordo com a Câmara Brasileira da Indústria da Construção (CBIC, 2014), a FBCF da CC ao longo dos últimos treze anos teve crescimento médio de $11,45 \%$. Neste período, cabe destacar o crescimento de 2004 em relação a 2003 (19\%), bem como o de 2008 em comparação a 2007 (18,3\%) e, principalmente, de 2010 em relação a 2009 (20,4\%). O comportamento da FBCF da CC no período acima (ver Tabela 3) reflete o momento econômico mais auspicioso na economia nacional, observado em 2010, com o Brasil tendo realizado seu maior PIB da década.

Tabela 3 - Evolução do PIB brasileiro (2001 - 2013), \%

\begin{tabular}{c|c|c|c|c|c|c|c|c|c|c|c|c|c}
\hline Ano & 2001 & 2002 & 2003 & 2004 & 2005 & 2006 & 2007 & 2008 & 2009 & 2010 & 2011 & 2012 & 2013 \\
\hline $\begin{array}{c}\text { Var. Anual } \\
\text { PIB (\%) }\end{array}$ & 1,5 & 2,7 & 1,1 & 5,7 & 3,2 & 4,0 & 6,1 & 5,2 & $-0,3$ & 7,5 & 2,7 & 1,0 & 2,3 \\
\hline
\end{tabular}

Fonte: IBGE (2014). 
Note-se que, no período seguinte à crise financeira de 2008, decorrência do "estouro da bolha" imobiliária nos EUA, a média de crescimento da FBCF foi ainda maior (aproximadamente 12,21\% ao ano), evidenciando o esforço da política nacional heterodoxa de mitigação dos efeitos da crise, com incentivos ao consumo, ciclos de redução da taxa básica de juros, ampliação do crédito ao consumidor e ao produtor, desoneração de impostos e projetos governamentais como o Programa Minha Casa Minha Vida (PMCMV) e o Programa de Aceleração do Crescimento (PAC), o que trouxe uma série de incentivos ao setor da CC (ABRAMAT, 2010; CASTRO; BARROS; VEIGA, 2014). Os reflexos desta política também foram notados em 2010, com um crescimento do PIB de 7,5\% em relação a 2009, além de impactos positivos no para a construção civil, como pode ser evidenciado na análise do valor adicionado bruto do setor, a que se detém a seção a seguir.

\subsubsection{Valor adicionado bruto (VAB)}

Pela perspectiva da produção, o VAB representa o produto total (bens e serviços) de um setor produtivo, após descontados os insumos utilizados e os subsídios governamentais. É um importante sinalizador de desempenho do setor econômico em análise. A Tabela 4 apresenta uma evolução da variação do valor adicionado da construção civil e da indústria brasileira como um todo.

Tabela 4 - Evolução do valor adicionado bruto - VAB (2001 - 2013), \%

\begin{tabular}{|c|c|c|c|c|c|c|c|c|c|c|c|c|c|c|}
\hline Ano & Setor & 2001 & 2002 & 2003 & 2004 & 2005 & 2006 & 2007 & 2008 & 2009 & 2010 & 2011 & 2012 & 2013 \\
\hline \multirow{3}{*}{$\begin{array}{c}\text { Var. Anual } \\
\text { Valor Adicionado } \\
\text { Bruto }(\%)\end{array}$} & C.C & 5,3 & 5,3 & 4,7 & 5,1 & 4,9 & 4,7 & 4,9 & 4,9 & 4,9 & 5,7 & 5,8 & 5,7 & 5,4 \\
\hline & I.T & 26,9 & 27,1 & 27,8 & 30,1 & 29,3 & 28,8 & 27,8 & 27,9 & 25,4 & 28,1 & 27,5 & 26,0 & 24,9 \\
\hline & $\%$ C.C & $19,7 \%$ & $19,6 \%$ & $16,9 \%$ & $16,9 \%$ & $16,7 \%$ & $16,3 \%$ & $17,6 \%$ & $17,6 \%$ & $19,3 \%$ & $20,3 \%$ & $21,1 \%$ & $21,9 \%$ & $21,7 \%$ \\
\hline
\end{tabular}

Fonte: IBGE (2014) (Legendas: C.C.: Construção Civil / I.T.: Indústria Total).

Observa-se que a contribuição do setor para o VAB da economia nacional é, em média, de 5,2\%, tendo alcançado picos de 5,7\% em 2010 e 2012, e 5,8\% em 2011. A tabela também revela que a CC é responsável por, em média, 18,9\% do VAB de todo o setor industrial, tendo chegado a maiores patamares nos últimos quatro anos, 2010 a 2013. O Gráfico 1 permite uma análise relacionando a evolução da variação do PIB brasileiro com a evolução do VAB da construção civil.

\section{Gráfico 1 - Evolução PIB Brasil e VAB da construção (2001 - 2013), \%}

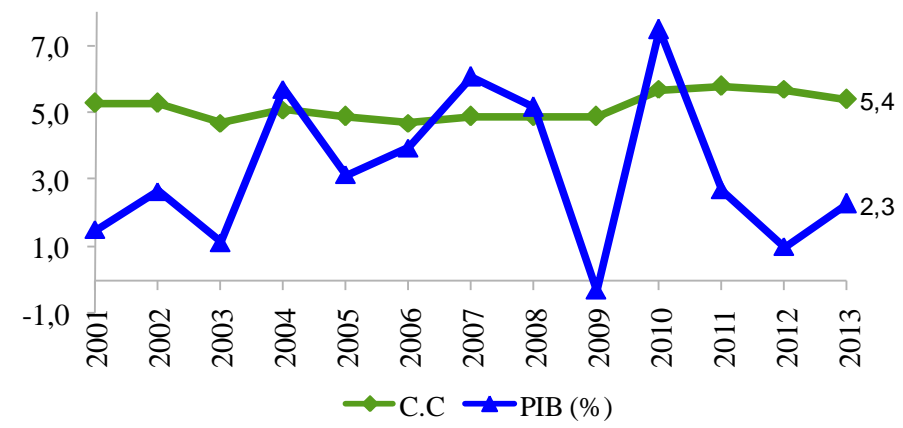

Fonte: IBGE (2014) (Legenda: C.C.: Construção Civil).

O crescimento percentual do PIB brasileiro mostra-se inconsistente, com destaque para a queda de 2009 em relação a $2008(-0,3 \%)$ e, talvez impulsionado por este fato (base muito baixa), o crescimento elevado (e aparentemente errático) de 7,5\% apresentado no ano de 2010 em comparação com 2009. O setor da construção, por seu turno, tem se mostrado mais perene, não parecendo sofrer oscilações tão diretamente influenciadas 
pelas variações no PIB (embora sejam mais perceptíveis as variações nos períodos 2002/03/04 e 2009/10). A análise pode sugerir que não existe relação significativa entre as variáveis (PIB-Brasil e VAB-CC), embora não tenham sido realizados neste estudo testes estatísticos de correlação que validem empiricamente esta hipótese.

Um indicador capaz de captar as duas visões macroeconômicas ora abordadas (ótica da demanda e ótica da produção) é a taxa de investimento. Este indicador representa a participação da FBCF na constituição do PIB brasileiro. Em outras palavras, quanto o investimento em capital produtivo (máquinas, equipamentos) contribui para a formação do PIB.

O racional de cálculo da taxa de investimento total é dado por

$$
T . I=\frac{F B C F}{P I B}
$$

onde, T.I = taxa de investimento total;

$\mathrm{FBCF}$ = formação bruta de capital fixo;

PIB = produto interno bruto.

Em termos específicos, o calculo da taxa de investimento da construção civil em função do PIB total é obtido por

$$
T . I=\frac{F B C F(00)}{P I B}
$$

onde $\mathrm{FBCF}(\mathrm{cc})$ = formação bruta de capital fixo da construção civil.

O Gráfico 2 aponta a evolução da taxa de investimento total e da taxa de investimento da construção civil para o período de 2001 a 2013.

Gráfico 2 - Evolução da taxa de investimento (2001 - 2013), \%

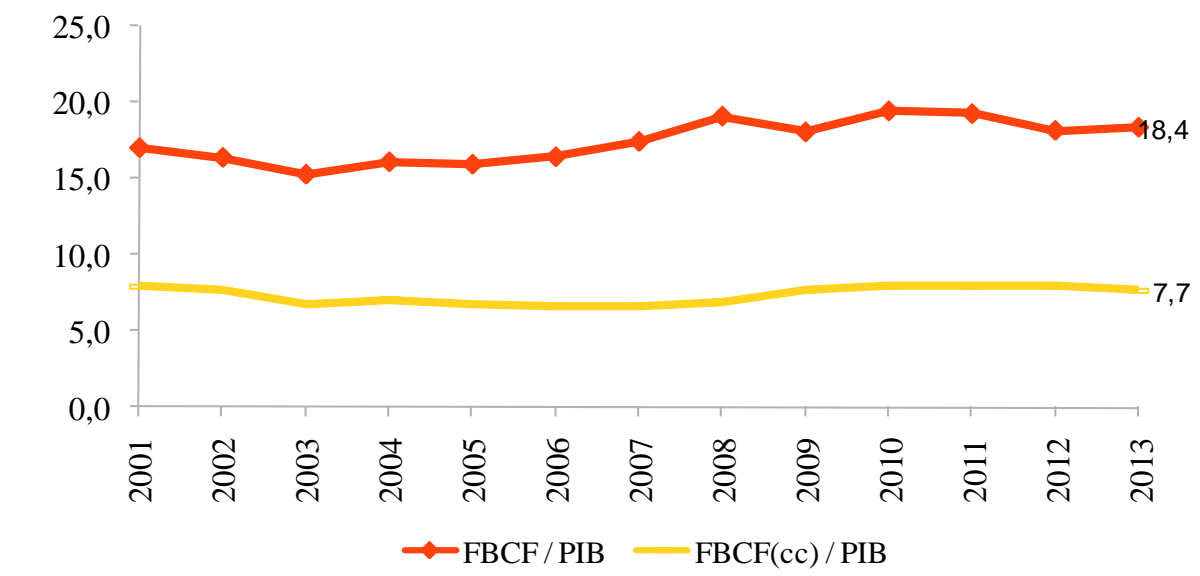

Fonte: CBIC (2014) (Legendas: C.C.: Construção Civil / I.T.: Indústria Total).

A taxa de investimento da CC tem se mantido em patamar médio de 7,4\% do PIB, considerando o período de 2001 a 2013. Observe-se, todavia, que nos últimos cinco anos, seu desempenho ficou acima desta média, fechando o ano de 2013 em 7,7\%.

Todas estas análises econômicas, tanto pela ótica da demanda, quanto pela da produção, revelam a importância do setor da CC como indutor do crescimento, aspectos discutidos no início desta seção. Embora indicadores como PIB tenham sofrido variações mais nítidas, o setor da construção não refletiu tais oscilações em sua parcela, certamente, em virtude dos planos de incentivo ao consumo, adotados pelos decisores da política econômica nacional nos últimos seis anos. 


\subsubsection{Emprego no setor da construção civil}

Dados de emprego são importantes fontes de referência de desempenho da economia e refletem o comportamento das atividades setoriais. Em 2008, os efeitos da crise mundial afetaram o emprego em todos os setores da economia brasileira. Na construção civil, somente nos meses de novembro e dezembro daquele ano foi contabilizada uma redução de 105.163 postos de trabalho formais (CBIC, 2010).

A recuperação do setor da construção revela-se no acumulado do ano de 2009 , pois o emprego formal na construção aumentou 9,17\%. Em 2010, houve uma superação dos efeitos da crise internacional de 2008, com o emprego crescendo $6 \%$, ultrapassando assim os 11,3 milhões de postos de trabalho (ABRAMAT, 2011). Obras do Programa de Aceleração do Crescimento (PAC), além dos lançamentos imobiliários observados em 2010 e contratos realizados nos dois anos anteriores, juntamente com o Programa Minha Casa Minha Vida (PMCMV), por certo contribuíram para impulsionar as atividades do setor e gerar a contratação de mão de obra (CBIC, 2010). Segundo o Ministério do Planejamento, o PAC tem sido essencial para a geração do emprego formal em obras de infraestrutura, devido ao programa, aumentou em média 5,3\% ao ano, no período de 2011 a 2013. Já o crescimento do emprego formal total no Brasil, nesse mesmo período, cresceu em média $3,1 \%$ ao ano (MINISTÉRIO DO PLANEJAMENTO, 2013).

O forte poder de encadeamento, que é a influência que CC possuí sobre a cadeia produtiva do setor, atesta o seu potencial como atividade geradora de complementaridades e externalidades positivas em toda a cadeia, tanto sobre os setores fornecedores de insumos como os setores consumidores (SANTOS et al., 2011).

A Tabela 5 apresenta uma evolução dos investimentos em relação à taxa de desemprego nos anos de 2007 a 2013 para o setor da Construção Civil.

Tabela 5 - Evolução do investimento e taxa de desemprego na Construção Civil

\begin{tabular}{|c|c|c|c|c|c|c|c|c|}
\hline & Ano: & 2007 & 2008 & 2009 & 2010 & 2011 & 2012 & 2013 \\
\hline $\begin{array}{c}\text { Investimentos } \\
\text { governamentais } \\
\text { (PAC) }\end{array}$ & $\mathbf{R} \$$ & \multicolumn{3}{|c|}{403 bilhões } & \multicolumn{4}{|c|}{773 bilhões } \\
\hline Taxa de desemprego & $\%$ & 5,7 & 4,0 & 4,8 & 2,9 & 3,1 & 3,1 & 3,5 \\
\hline
\end{tabular}

Fonte: Elaborado pelos autores; informações do relatório PAC 2, $9^{\circ}$ Balanço 2011-2014 - ano III (2013)

Conforme Cardoso (2013), para continuar gerando renda e emprego o Governo Federal, dentro do PAC 2, iniciou em 2013 a execução de algumas diretrizes de seu subprograma chamado de Brasil Maior, com a desoneração da folha de pagamento das empresas do setor, no que tange a parte patronal do INSS que atualmente representa $20 \%$ da base de salários para pagamento à Previdência Social, instituídos através da Lei $\mathrm{n}^{\circ} 12.546$, de 14/12/2011, MP 563, de 03/04/2012 e Decreto 7.771, de 30/04/2012.

Segundo Kureski et al. (2008), a geração de empregos ocorre devido ao aumento da demanda final, por exemplo, a procura por habitação. Assim, primeiramente são gerados os empregos diretos, que correspondem à divisão do total de empregados pelo valor bruto da produção da atividade. A geração de empregos indiretos se dá pelo incremento da demanda por insumos intermediários da atividade que apresentou aumento na demanda final, que resulta no aumento da produção das demais atividades. $\mathrm{O}$ incremento no aumento da produção também resulta no aumento do emprego decorrente do aumento da renda, além de que setores da administração, saúde e 
educação pública como maiores fomentadores de empregos indiretos gerados no setor, todos contribuem na geração de renda (SANTOS et al., 2011).

\subsubsection{Investimentos no setor da construção civil}

Os investimentos no setor são primordiais, pois complementam a base produtiva, produzindo impactos positivos para o desenvolvimento econômico-social (TEIXEIRA; CARVALHO, 2005). Esta afirmativa é aplicada historicamente, por meio dos programas governamentais que investem cada vez mais fortemente no setor, buscando alavancar o crescimento do PIB (GONDIN, 2004; KURESKI et al., 2008).

Os investimentos realizados nos programas da segunda fase do PAC 2 e o PMCMV foram de $\mathrm{R} \$ 773,4$ bilhões para o período de 2011 a 2013, somente em habitação, conforme indicadores de direcionamento de recursos do Sistema Brasileiro de Poupança e Empréstimo (SBPE), os investimentos foram crescentes em todos os anos de 2008 (R \$ 208,648 milhões) a 2013 ( $\mathrm{R} \$ 530,043$ milhões), que representou um aumento de 154\%, atendendo principalmente ao investimento para construção de moradias por meio do PMCMV, iniciado em 2009 com 394.135 unidades com financiamento imobiliários concedidos, para em 2013, atingir um total 6.306.160 unidades.

Em relação à indústria de materiais de construção, o faturamento saltou dos $\mathrm{R} \$ 39,48$ bilhões registrados em 2007, no começo do PAC, chegando aos atuais $\mathrm{R} \$ 57,42$ bilhões em 2013, representando um aumento de 45,44\%, seguindo os investimentos realizados neste período. Já para o número de estabelecimentos voltados ao negócio da construção civil, este passou de 135.164 (2008) para 208.537 (2013) unidades, um crescimento de $154 \%$. Este crescimento do número de empresas em atividade no setor contribui para o aumento da demanda de mão de obra pelas empresas e a busca pela competitividade.

\section{RESULTADOS E DISCUSSÕES}

O volume de investimentos e incentivos anunciados em 2007, pelo PAC, proporcionou um início de um novo crescimento para setor da Construção Civil, apesar do ambiente econômico de crise em 2008. No entanto, esses efeitos só realmente se configurariam em 2009, em um cenário de recessão mundial. Configurava-se, assim, a redução do emprego e da renda no país. Porém, verificou-se o inverso: houve a geração de 955 mil postos de trabalho formais. $\mathrm{O}$ fortalecimento da demanda doméstica foi o pilar para $\mathrm{O}$ mercado interno do setor, com resultados importantes no ano seguinte (CBIC, 2010).

O nível de desempenho atingido em 2010 pelo setor deixa evidente a importância do comprometimento com políticas de investimento e incentivos para a habitação. Os números alcançados no PIB do setor $(11,6 \%)$ e uma taxa de desocupação $(2,9 \%)$ mostram que a manutenção do crescimento exigiria de uma infraestrutura compatível, principalmente quanto à produção energética e à produção de bens, isto é, a produtividade do setor teria de melhorar. Logo em 2011, a capacidade de crescimento manteria o ciclo virtuoso iniciado em 2004 (CBIC, 2011), apesar da crise internacional em países da Europa, que por sua vez, obrigou a tomada de medidas internas de contenção da inflação por meio da elevação dos juros. Apesar do significativo nível de investimento, os resultados dos indicadores do setor, no ano de 2012, resultaram em $1,4 \%$ de crescimento do PIB do setor. O reflexo verificado pelo governo, diante do resultado de baixa produção no setor, seria o aumento da taxa de desemprego, repercutindo na geração de renda. Tal situação levou o governo a tomar medidas de desoneração da folha de pagamento das empresas (CARDOSO, 2013), mantendo a taxa de desemprego em 3,1\%, igual ao resultado em relação a 2011. Porém, o ano de 2013 apresentou os piores resultados do setor em seus indicadores desde o ano de 2009, principalmente com a retração no número de empregos, com a taxa de desemprego 
chegando a 3,5\%, também se verificou o baixo nível de atividade, ficando em 44,7\%, quando nos anos anteriores, o nível de atividade chegou a 54,4\%.

Os dados apresentados demonstram, ao longo deste período analisado, a crescente importância do setor para a sustentação da economia: em média, o setor cresceu a uma taxa anual de 5\%; a participação no PIB passou de 4,7\% para 5,7\% nos últimos 10 anos; dados da RAIS contabilizam, entre 2008 e 2011, aumento de 52\% no nível emprego (DIEESE, 2012). Em termos de perspectiva para o futuro do setor, o principal aspecto econômico diz respeito à significativa demanda da infraestrutura e habitação, ressaltando que o primeiro é determinante sustentação da economia nacional.

\section{CONSIDERAÇÕES FINAIS}

O presente artigo apresentou uma análise exploratória dos aspectos econômicos da Construção Civil a partir dos dados dos indicadores mais utilizados em análises realizadas em diversos periódicos especializados, artigos científicos e instituições de pesquisa e estudo do país.

Os resultados obtidos desta análise apontam para o reconhecimento do significado do setor para a economia e a inter-relação entre estes indicadores. A realidade é que poucos estudos das características do setor nacional tratam da relação entre indicadores e seus efeitos sobre a economia, inferindo sobre a evolução histórica e a interpretação de seus significados para o desenvolvimento do setor e da economia geral.

Algumas limitações deste trabalho podem suscitar a necessidade de futuras pesquisas que venham a suplantá-las. Por se propor a realizar uma análise documental a partir de relatórios de indicadores da construção, não se aplicaram neste artigo análises estatísticas visando a correlacionar variáveis para identificar relações de causa e efeito, o que implicaria relevante valor empírico à nova pesquisa. Considerando que toda a análise aqui realizada adotou medidas agregadas nacionais, também importante seria investigar a participação das unidades da federação (UFs) e/ou regiões geográficas brasileiras dentro do contexto nacional, a fim de avaliar suas contribuições para o produto nacional do setor da Construção Civil.

\section{REFERÊNCIAS}

ASSOCIAÇÃO BRASILEIRA DA INDÚSTRIA DE MATERIAIS DE CONSTRUÇÃO. Perfil da cadeia produtiva da construção e da indústria de materiais e equipamentos. São Paulo, 2010. Disponível em:

<http://www.abramat.org.br/site/datafiles/uploads/files/Perfil\%20da\%20Cadeia\%20Produtiva\% 202010\%20baixa.pdf>. Acessado em 20 mar. 2014.

ASSOCIAÇÃO BRASILEIRA DA INDÚSTRIA DE MATERIAIS DE CONSTRUÇÃO. Perfil da cadeia produtiva da construção e da indústria de materiais e equipamentos. São Paulo, 2011. Disponível em:

<http://www.abramat.org.br/site/datafiles/uploads/files/cadeia_produtiva_2011.pdf > . Acessado em 20 mar. 2014.

BON, R. The future of international construction: secular patterns of growth and decline.

Habitat International, v. 16, n. 3, p. 119-128, 1992.

CARDOSO, F. H. Incentivo do estado e desenvolvimento: uma análise sobre o crescimento da área da construção civil. Departamento de Ciências Sociais. Universidade Estadual de Londrina. Londrina, 2013.

CASTRO, B. H. R. DE; BARROS, D. C.; VEIGA, S. G. DA. Panorama da indústria de bens de capital para a construção civil. BNDES Setorial Bens de Capital, v. 37, n. 1, p. 89-128, 2014.

CÂMARA BRASILEIRA DA INDÚSTRIA DA CONSTRUÇÃO. Informações sobre a formação bruta de capital fixo no Brasil e na construção civil segundo dados oficiais do 
IBGE. Disponível em: <http://www.cbicdados.com.br/menu/pib-e-investimento/investimento>. Acessado em: 27 mar. 2014.

CÂMARA BRASILEIRA DA INDÚSTRIA DA CONSTRUÇÃO. Construção civil: análise e perspectivas. Banco de dados. Brasília. 2010.

CELLARD, André. A análise documental. In: POUPART, J.; DESLAURIERS, J. P., GROULX, L. H.; LAPARRIÈRE, A.; MAYER, R.; PIRES, A. P. A pesquisa qualitativa: enfoques epistemológicos e metodológicos. 2. ed. Petrópolis: Vozes, 2010. (Coleção Sociologia).

CRESWELL, J. W. Educational research: planning, conducting, and evaluating quantitative and qualitative research. 4th ed. Boston: Pearson Education, 2012.

DEPARTAMENTO INTERSINDICAL DE ESTATÍSTICA E ESTUDOS

SOCIOECONÔMICOS. Estudo setorial da construção - 2012. Estudos e Pesquisas, n. 65.

São Paulo, mai. 2013. Disponível em: 〈http://www.dieese.org.br>. Acessado em 06 dez. 2013

FERRAZ, H. V. D.; FERNANDES, E. A. Análise do mercado de aço para construção civil no sul de Minas Gerais. Revista Economia e Desenvolvimento, n. 20, p. 42-63, 2008.

GONDIM, I. A.; MARCHON, P. H. A.; BARROS NETO, J. P.; JORGE NETO, P. M. Análise da economia nacional e a participação da indústria da construção civil. In: ENCONTRO

NACIONAL DE TECNOLOGIA DO AMBIENTE CONSTRUÍDO, 10, 2004, São Paulo, Anais..., São Paulo: ANTAC, 2004.

INSTITUTO BRASILEIRO DE GEOGRAFIA E ESTATÍSTICA. Contas nacionais trimestrais. Série Relatorios Metodológicos, número 28. Rio de Janeiro, 2008.

INSTITUTO BRASILEIRO DE GEOGRAFIA E ESTATÍSTICA. Contas nacionais trimestrais: indicadores de volume e valores correntes. Rio de Janeiro, 2013.

KURESKI, R.; RODRIGUES, R. L.; MORETTO, A. C.; SESSO FILHO, U. A.; HARDT, L. P. A. O macrossetor da construção civil na economia brasileira em 2004. Ambiente Construído, v. 8, n. 1, p. 7-19, 2008.

Ministério do Planejamento. Geração de empregos formais. Disponível em: <http://www.brasil.gov.br/economia-e-emprego/2014/02/mercado-de-trabalho-brasileiro-semanteve-robusto-em-2013-com-geracao-de-empregos-formais-e-crescimento-da-renda-real〉. Acessado em 02 dez. 2013.

SANTOS, A. M.; ROSSI, G. F.; TOYOSHIMA, S. H.; EVANGELISTA, W. L. Impactos comparativos do setor da construção civil sobre o emprego no Brasil: 2002-2009. Revista de Ciências Humanas, v. 11, n. 1, p. 24-35, jan./jun. 2011.

SOUZA, J. M. (Eds.). Economia brasileira. São Paulo: Pearson Prentice Hall, 2012.

O'SULLIVAN, A.; SHEFFRIN, S.; NISHIJIMA, M. Introdução à economia: princípios e ferramentas. São Paulo: Prentice Hall, 2004.

TEIXEIRA, L. P.; CARVALHO, F. M. A. A construção civil como instrumento do desenvolvimento da economia brasileira. Revista Paranaense de Desenvolvimento, n. 109, p. 9-26, 2005.

ZERKOWSKI, R. M. Homogeneização metodológica dos indicadores econômicos retrospectivos. Revista Brasileira de Economia, n. 33, v. 3, p. 441-455, jul./set. 1979. 